\title{
A „nemlineáris kémiai dinamikai jelenségek” kutatása az ELTE Analitikai Kémiai Tanszékén II. (2012-2020)
}

\author{
CSÖRGEINÉ KURIN Krisztina, SZALAI István és ORBÁN Miklós* \\ ELTE, TTK Kémiai Intézet, Analitikai Kémiai Tanszék, Pázmány Péter sétány 1/A, 1117 Budapest, Magyarország
}

\section{Bevezetés}

Korábbi beszámolónkban összefoglaltuk a nemlineáris kémiai dinamika területén 2012-ig végzett kutatásaink motivációját, célját és az elért eredményeinket. ${ }^{1}$ A jelen közleményben a 2012-től napjainkig végzett munkáinkról adunk számot. Kutatásaink célja továbbra is az önszerveződő kémiai rendszerekre vonatkozó ismeretek bővítése, tárgya az időben és térben spontán kialakuló koncentráció eloszlás - az oszcilláló kémiai reakciók és a kétdimenziós kémiai struktúrák - előállítása, kialakulásuk molekuláris hátterének tisztázása, a jelenségek modellezése, szimulációja és a megszerzett ismeretek alapján általános összefüggések megállapítása. Eredményeinket az alábbi csoportosításban tárgyaljuk: 1. Oszcilláló kémiai rendszerek új változatainak létrehozása, 2. Kémiai mintázatképződés tervezése és laboratóriumi előállítása, 3. Nemlineáris kémiai reakciók és jelenségek kinetikájával és modellezésével kapcsolatos munkák ismertetése.

\section{1. Új oszcilláló kémiai rendszerek előállítása}

Új oszcilláló kémiai rendszerek alatt értjük azokat, amelyek az összetételükben különböznek a már ismertektől, olyan főkomponenst (oxidáló- vagy redukálószert) tartalmaznak, amelyeket eddig reagensként nem alkalmaztak oszcilláló reakciókban. Új variánsnak tekinthetők azok is, amelyekben kiterjesztjük az oszcilláló komponensek számát olyan ionokkal és molekulákkal, amelyek a ma ismert oszcillációs mechanizmusokban közvetlenül részt venni nem képesek, de oszcillációra kényszeríthetők egy primer oszcillátorhoz való kapcsolással. Az oszcilláló kémiai rendszerek döntő többsége csak nyitott üzemmódban ( CSTR: Continuously Stirred flow-Through Reactor-ban) müködik. Néhányuk félig-zárt és zárt rendszerben is oszcillálóvá tehető, az igy kialakítottak a laboratóriumi megvalósításuk módszerében számítanak újszerünek.

\section{1. Összetételükben új oszcilláló rendszerek}

A mangán kémiáján alapuló oszcillátor család új tagját állítottuk elö. Korábban a mangán oszcillátorokban redukálószerként kizárólag szervetlen vegyületeket használtak. Előállítottuk azt a mangán variánst, amelyben a redukáló szubsztrát aminosav. Kimutattuk, hogy a glicin permanganátos oxidációja, speciális feltételek mellett (áramlásos reaktorban, közel semleges $\mathrm{pH}-\mathrm{n}, \mathrm{T}=45{ }^{\circ} \mathrm{C}$-on, foszfátionok jelenlétében) oszcillációs kinetika szerint játszódik le. ${ }^{2}$ Oszcillációkat az elegybe merített Pt elektród potenciáljában és az oldatban $\lambda=545 \mathrm{~nm}$ és $418 \mathrm{~nm}$ hullámhosszon (a reagens $\mathrm{KMnO}_{4}$ ill. az autokatalitikus részecskeként funkcionáló oldható Mn(IV) abszorpciós maximumán) mértünk. Modellt javasoltunk az oszcillációs viselkedés értelmezésére. Felhasználva az irodalomban fellelhető kinetikai adatokat és az általunk használt kísérleti paramétereket, sikeresen szimuláltuk mind a nyitott, mind a zárt rendszerben megfigyelt jelenségeket. Megállapítottuk, hogy a glicin helyett threonint vagy aszparaginsavat alkalmazva is fellépnek oszcillációk.

Perborátos oxidáción alapuló oszcilláló reakciókat fejlesztettünk ki. A peroxivegyületek közül a $\mathrm{H}_{2} \mathrm{O}_{2}$ és a $\mathrm{K}_{2} \mathrm{~S}_{2} \mathrm{O}_{8}$ több oszcilláló kémiai rendszer fö komponense, perborátot $\left(\mathrm{NaBO}_{3}\right)$ azonban periodikus reakciók előállításához eddig még nem alkalmaztak. Kimutattuk, hogy a nátrium perborát, amely lényegesen enyhébb oxidálószer, mint a $\mathrm{H}_{2} \mathrm{O}_{2}$ és a $\mathrm{K}_{2} \mathrm{~S}_{2} \mathrm{O}_{8}$, a peroxid-oszcillátorok alternatív oxidálószere lehet. $\mathrm{A} \mathrm{BO}_{3}{ }^{-}-\mathrm{S}_{2} \mathrm{O}_{3}{ }^{2-}-\mathrm{Cu}$ (II) CSTR rendszerben potenciál (Pt vs Ref) és pH-oszcillációkat, a $\mathrm{BO}_{3}{ }^{-}-\mathrm{SCN}^{-}-\mathrm{Cu}(\mathrm{II})$ zárt rendszerben oszcilláló potenciált és monoton $\mathrm{pH}$ csökkenést regisztráltunk. Mechanizmust javasoltunk és szimulációkat végeztünk a kísérletileg megfigyelt dinamikai viselkedés értelmezésére. Meghatároztuk a perborát vizes oldatában jelenlevő specieseloszlás vs $\mathrm{pH}$ összefüggést és rámutattunk az oszcillációs pH-n domináns $(\mathrm{HO})_{3} \mathrm{~B}(\mathrm{OOH})^{-}$ és $(\mathrm{HO})_{2} \mathrm{~B}(\mathrm{OOH})_{2}{ }^{-}$intermedierek meghatározó szerepére az oszcillációk kialakulásában. ${ }^{25}$

\subsection{Indukált oszcillációk generálása kapcsolt egyensúlyi rendszerekben}

pH-oszcillátorral, mint ritmusadóval pH-érzékeny fizikai, kémiai és biológiai egyensúlyok vezérelhetők, ezekben periodikus változások indukálhatók. Korábban kimutattuk, hogy redox kémián alapuló oszcillátort sav-bázis jellegü komplex-, vagy csapadékképződési reakcióval kapcsolva lehetővé válik az oszcillációban résztvenni képes elemek és specieszek számának jelentős kiterjesztése, amely új nem-lineáris viselkedési formák megjelenéséhez is vezethet. ${ }^{3}$

\footnotetext{
* E-mail:kurin@caesar.elte.hu; iszalai@caesar.elte.hu; orbanm@caesar.elte.hu
} 
Periodikusan változó species eloszlást valósítottunk meg a pH-függő $\mathrm{Ni}^{2+}$ és hisztidin (His) közötti lépcsőzetes komplexképződési egyensúly és a $\mathrm{BrO}_{3}{ }^{-}-\mathrm{SO}_{3}{ }^{2-}$ oszcillátor (BS) kapcsolásával CSTR-ban. A kombinált rendszerben a pH mellett a $\left[\mathrm{Ni}^{2+}\right]$, $[\mathrm{NiHis}]^{+}$és $\left[\mathrm{Ni}(\mathrm{His})_{2}\right]$ is periodikusan változik: alacsony $\mathrm{pH}-\mathrm{n}(\mathrm{pH} 4)$ a $\left[\mathrm{Ni}^{2+}\right]$ maximális, a $\left[\mathrm{Ni}(\mathrm{His})_{2}\right]$ minimális, magas $\mathrm{pH}-\mathrm{n}(\mathrm{pH}>7)$ a specieseloszlás fordított. A pH-ciklusok által indukált periodikusan változó specieseloszlást három hullámhosszon szimultán mért abszorpciók időbeni változása alapján mutattuk ki. A kapcsolt rendszer dinamikai viselkedését szimuláltuk, felhasználva a BS oszcillátor mechanizmusát leíró sebességi egyenleteket és a komplex egyensúlyt jellemző paramétereket. ${ }^{4}$

Indukált oszcillációk kialakulásának újabb lehetőségét figyeltük meg a $\mathrm{BrO}_{3}{ }^{-}-\mathrm{SO}_{3}{ }^{2-} \mathrm{pH}$-oszcillátor és a $\mathrm{Co}(\mathrm{II})$ hisztidin komplex kapcsolásával. Az összetett rendszerben a $\mathrm{pH}$ periodikus változását a kobaltion oxidációs számának +2 és +3 közötti oszcillációja kíséri. A Co(III)-komplex ciklusonkénti megjelenését és eltűnését a rá jellemző hullámhosszon mért fényabszorpció időbeni változása alapján követtük. A jelenséget a $\mathrm{SO}_{3}{ }^{2-}$ kettős szerepével magyaráztuk: bromátos oxidációja fenntartja a pH-oszcillációt és jelenléte indukálja a központi Co(II) ionnak a savas közegben is rendkívül stabilis Co(III)-keláttá történő oxidációját. ${ }^{5}$

$\mathrm{A} \mathrm{BrO}_{3}{ }^{-}-\mathrm{SO}_{3}{ }^{2-}-\mathrm{Fe}(\mathrm{CN})_{6}{ }^{4-} \mathrm{pH}$-oszcillátorba $\mathrm{pH}$-érzékeny hidrogélt helyezve a pH-oszcilláció a gélfelület adszorpciós-deszorpciós képességének periodikus változását idézte elö, ami ezüst-nanorészecskék reverzibilis megkötésének és deszorpciójának mérésével volt követhető. A jelenség példa arra, hogy egy primer oszcillátor a hozzákapcsolt rendszerben nemcsak kémiai, hanem fizikai tulajdonság ritmikus változását is indukálni képes. ${ }^{6}$

\subsection{Előállításuk módszerében új oszcilláló rendszerek: CSTR oszcillátorok átalakítása zárt rendszerben is müködő formába}

Az összes ismert $\mathrm{pH}$-oszcillátort (25 rendszer) áramlásos reaktorban fedezték fel. A CSTR rendszernél kísérletileg lényegesen egyszerübb elrendezésű zárt rendszerü pH-oszcillátorok kifejlesztésének igénye a gyakorlati alkalmazhatóságukkal kapcsolatban merült fel. Korábbi publikációnkban módszert javasoltunk CSTR oszcillátorok átalakítására zárt rendszerben is müködö formába. ${ }^{7}$ Ez úgy volt megvalósítható, hogy a pH-oszcilláció 1-1 ciklusában teljesen elreagált komponenst nem külső forrásból (betáplálással), hanem a reaktorban folyamatosan generáltuk a reakcióedényben elözetesen elkészített, a reagenssel telített gélböl történő kioldással. Megvalósítottuk a felhasználhatóság szempontjából legígéretesebb $\mathrm{BrO}_{3}^{-}-\mathrm{SO}_{3}{ }^{2-} \mathrm{CSTR}$ oszcillátor átalakítását. A szulfit folyamatos pótlását szilikagélből való kioldással oldottuk meg. Oszcillációkat a gélréteg feletti kevert bromátion-oldatban mértünk. A géltáplált reaktor több órán át (5-6 óra), $\mathrm{t}=50-60$ perc periódus idővel, $\Delta \mathrm{pH} \sim 3$ amplitúdóval müködött. A zárt rendszerü változat előállításának közbülső lépéseként létrehoztuk a félig-zárt formát, amely a szulfitoldatnak a reakcióedénybe lévő bromátion oldatba történő lassú és egyenletes bevezetésével volt elérhető. A félig-zárt rendszerben, bizonyos paramétereknél, a pH 24 órán keresztül, fél-órás periódusidővel, ciklusonként $\Delta \mathrm{pH}$ 3 egységgel változott úgy, hogy az össztérfogat csak kb 1 $\mathrm{cm}^{3}$-rel nőtt óránként. (Az itt alkalmazott betáplálási sebességből becsülhető a zárt változathoz szükséges kioldódási sebesség, amely variálható a gélben tárolt reagens koncentrációjával, a gélréteg vastagságával, a hőmérséklettel és a keverési sebességgel). Elvégeztük a kísérleti eredményeket szimuláló modellszámításokat, felhasználva az irodalmi sebességi együtthatókat és a kísérleteinkben használt paramétereket. A 6 lépést tartalmazó modellel a $\mathrm{BrO}_{3}{ }^{-}-\mathrm{SO}_{3}{ }^{2-}$ oszcillátor CSTR, félig-zárt és a zárt kivitelezésű változatának dinamikai viselkedése közel kvantitatíve leírható. ${ }^{8}$

A Cu(II)-katalizált $\mathrm{S}_{2} \mathrm{O}_{8}{ }^{2-}-\mathrm{S}_{2} \mathrm{O}_{3}{ }^{2-}$ összetételü CSTR oszcillátort félig-zárt és zárt konfigurációjú reaktorban müködő formába alakítottuk. Ez a rendszer nem $\mathrm{pH}$-oszcillátorként, hanem savas közegben müködö, gyökös mechanizmus szerint lejátszódó, $\Delta \mathrm{pH}$ maximum 0,3 amplitudójú CSTR oszcillátorként volt ismert. Újabb megfigyeléseink szerint a CSTR-ben rekord nagyságú pH-oszcillációk jelentkeznek $(\Delta \mathrm{pH} 4-5)$, ha a reaktorba bevezetett elegyhez $\mathrm{NH}_{4} \mathrm{OH}$-ot is adunk. A módosított összetételű CSTR rendszert is sikerült félig-zárt és zárt konfigurációban működtetni. Jelenleg keressük a nagy amplitúdójú pH-oszcillációk megjelenésének kémiai magyarázatát. A zárt rendszerben mért pH-oszcillációkat az 1. ábrán mutatjuk be.

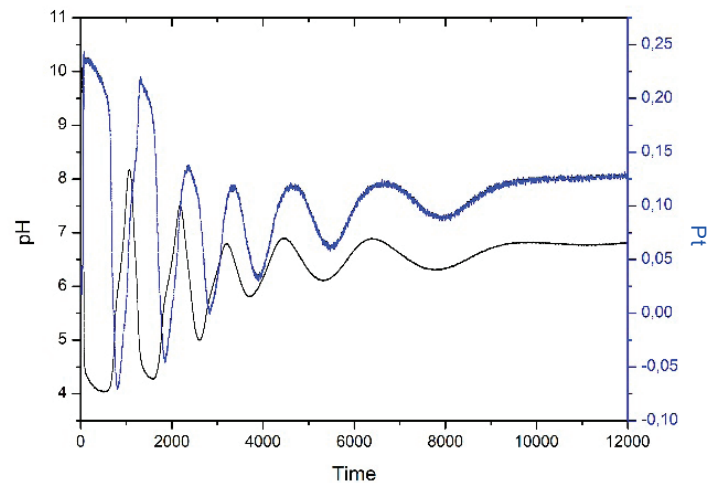

1. ábra. $\mathrm{pH}$ - és potenciáloszcillációk a $\mathrm{Cu}(\mathrm{II})-\mathrm{katalizált} \mathrm{S}_{2} \mathrm{O}_{8}{ }^{2-}-\mathrm{S}_{2} \mathrm{O}_{3}{ }^{2-}$ zárt rendszerben

\section{Térben periodikus strukturák laboratóriumi előállítása}

\subsection{Kalcium hullámok előállítása}

Az indukált oszcillációk tervezésére javasolt módszerünket ${ }^{3}$ alkalmaztuk indukált térbeni struktúra, kalcium hullámok előállítására. A Ca(II)-ionok koncentrációja a $\mathrm{BrO}_{3}{ }^{-}-\mathrm{SO}_{3}{ }^{2-}$ $\mathrm{Fe}(\mathrm{CN})_{6}{ }^{4-} \mathrm{pH}$-oszcillátor (BSF) és a $\mathrm{Ca}^{2+}+\mathrm{EDTE}$ egyensúly kombinációban, CSTR-ben, az oszcillátor frekvenciájával oszcillál. ${ }^{9}$ A két modulnak egy-oldalról táplált gélreaktorban (OSFR: One-Side Fed Reactor) történő összekapcsolásával a gélben (agaróz mátrixban) új-típusú periodikus jelenség kialakulását figyeltük meg: a $\mathrm{Ca}^{2+}$ és EDTE közötti 
egyensúlyi reakció követi a pH változását és a kialakuló pH-mintázatra szuperponálódik a $\mathrm{Ca}(\mathrm{II})$ ionok mintázata. Azokon a helyeken, ahol savas térbeni állapot uralkodik, a $\mathrm{Ca}^{2+}$-ionok szabad (aqua-komplex) formában vannak jelen, míg a nagyobb pH-jú területeken az EDTE-hez kötődnek. Ez a mechanizmus kalcium hullámok és mintázatok létrejöttéhez vezet. A $\mathrm{Ca}^{2+}$-ionok EDTE egyensúlyi reakció jelenlétében stacionárius jellegü mintázatok is kialakulhatnak, ami azzal magyarázható, hogy a pH-mintázatot adó alaprendszer dinamikai viselkedése jelentősen megváltozik a jelenlevő pH-érzékeny egyensúlyi folyamat által okozott visszacsatolás miatt. A Ca(II)ionokat szabályos alakzatban tartalmazó reakció-diffúzió mintázatokat (RD struktúrákat) eddig csak biológiai rendszerekben figyeltek meg. Eredményünk a kémiai rendszerekben kísérletileg előállított $\mathrm{Ca}$ (II)ion mintázat első példájaként szolgál ${ }^{10}$

\subsection{Kémiai hullámok a minimális bromát-oszcillátorokban}

A minimális bromát oszcillátorok $\left(\mathrm{BrO}_{3}^{-}-\mathrm{Br}\right.$-katalizátor) a legegyszerúbb olyan oszcilláló rendszerek, amelyek a bromátion és a bromidion közötti autokatalitikus reakción alapulnak. A bromátoszcillátorok számos képviselőjéről ismert, hogy reakció-diffúzió mintázatok kialakítására alkalmasak. Az egy-oldalról táplált gélreaktorban végzett kísérleteinkkel igazoltuk, hogy ilyen jelenségek a minimális variánsokban is megfigyelhetők. A térbeni dinamikai jelenségekben a gél és környezete között zajló diffúziós anyagcsere karakterisztikus ideje fontos szerepet játszik. Megmutattuk, hogy a ferroin-katalizált rendszernek a cérium- és mangán-katalizáltnál összetettebb mechanizmusa segíti az RD-mintázatok kialakulását. Kísérleti megfigyeléseink értelmezéséhez eredményes numerikus szimulációkat is végeztünk. ${ }^{11}$

\subsection{Stacionárius struktúra (Turing mintázat) kifejlesztése a $\mathrm{BrO}_{3}{ }^{-}-\mathrm{SO}_{3}{ }^{2-}-\mathrm{Fe}(\mathrm{CN})_{6}{ }^{4-}$ rendszerben}

A kétszubsztrátos pH-oszcillátorok (kevert Landolt rendszerek) OSFR-ben történő viselkedését tanulmányozva kimértük a $\mathrm{BrO}_{3}{ }^{-}-\mathrm{SO}_{3}{ }^{2-}-\mathrm{Fe}(\mathrm{CN})_{6}{ }^{4-}$ rendszer nem-egyensúlyi fázisdiagramját a negatív visszacsatolást biztosító ferrocianid betáplálási koncentrációjának függvényében és a reakció-diffúzió rendszer környezeteként szolgáló gélben különböző dinamikai jelenségeket figyeltünk meg. Kis ferrocianid koncentrációknál az autokatalitikus rendszerekre jellemző térbeni bistabilitás kialakulását, illetve a két stabil állapotot összekötő mozgó front megjelenését, egy kritikus ferrocianid koncentráció felett - az autokatalitikus species $\mathrm{H}^{+}$eltávolítása céljából Na-poliakrilátot adva - Turing szerkezet kifejlődését tapasztaltuk. ${ }^{12}$

\subsection{Reakció-diffúzió mintázatok létrehozása keresztirányú koncentrációgradiensek jelenlétében}

RD-mintázatokat nemcsak OSFR-ben, hanem olyan reaktorokban is kialakíthatunk, amelyekben a reaktánsokat a reakció közegeként szolgáló gél átellenes oldalain, állandó összetételű oldatokat tartalmazó tartályokból tápláljuk be. Ekkor a reakciók a keresztirányú koncentráció gradiensek által meghatározott térrészben lokalizálódnak, így lehetőség nyílik a gradiensek irányából, vagy azokra merölegesen tanulmányozni a mintázatképződést. A kétoldalas betáplálás (TSFR: Two-Side Fed Reactor) fö előnye, hogy így kivételesen jól kontrollálhatók és hangolhatók az előállított RD-jelenségek, ráadásul, érdekes dinamikai viselkedésformákat hozhatunk létre kevésbé komplex kinetikájú reakciókkal is. Ezt a reaktorkonfigurációt alkalmaztuk az $\mathrm{Al}(\mathrm{OH})_{3}$ csapadék rendszerben. $\mathrm{Az} \mathrm{Al}^{3+}$ és $\mathrm{OH}^{-}$-ionokból keletkező $\mathrm{Al}(\mathrm{OH})_{3}$ csapadékot , amely az $\mathrm{OH}^{-}$-ionok feleslegében visszaoldódásra képes, a kezdetben üres gélben képeztük ( az egyik oldalról az $\mathrm{Al}^{3+}$-ionokat, a másikból a $\mathrm{OH}^{-}$-ionokat tápláltuk be). $\mathrm{Az} \mathrm{Al}^{3+}$-peremkoncentrációtól függően, időben periodikus tranziens csapadékleválás-oldódás ciklusokat és cellás frontinstabilitásokat figyeltünk meg. ${ }^{13}$

A $\mathrm{H}^{+}$-autokatalizisre épülő Landolt-típusú oszcillátorokkal tetszőleges ideig fenntartható lokalizált pH-hullámokat sikerült előállítani. Ezzel a kémiai rendszerrel kimutattuk, hogy polielektrolit jelenlétében a gradienseknek köszönhető sávos struktúra kombinálható a Turing-típusú mintázatképződéssel. A létrehozott pöttyös stacionárius mintázat nem terjed ki a gél egészére, hanem annak egy meghatározott zónájában lokalizálódik. ${ }^{14}$ A természetben elöforduló mintázatképződési folyamatok jelentős része koncentrációgradienshez kötődik. Az ilyen RD-struktúrák kialakulását a Wolpert nevéhez füződő mintázatképződési koncepció modellezi. ${ }^{15}$

\subsection{Reakció-diffúzió jelenségek előállítása zárt kétrétegü gélreaktorban}

Két azonos méretü, különböző reaktánsokkal feltöltött géldarab összeillesztésével kialakított zárt rendszerben is előállítottunk keresztirányú koncentrációgradiennseknél fellépő RD-jelenségeket. Az ilyen elrendezésben állandó betáplálás híján a koncentrációgradiensek időben folyamatosan változnak, ezért az itt jelentkező dinamikai viselkedésformák is csak tranziensek lehetnek.
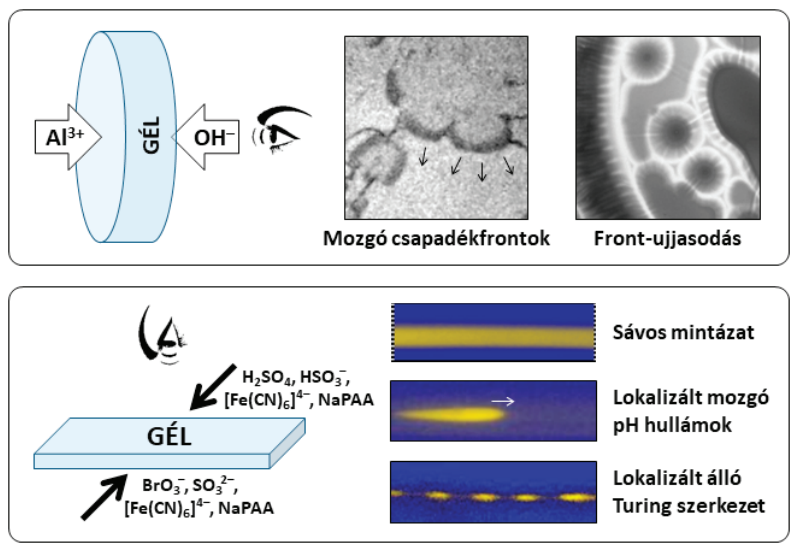

2. ábra. Keresztirányú koncentrációgradiensek létrehozása és a megfigyelt mintázatok az $\mathrm{Al}(\mathrm{OH})_{3}$ csapadék rendszerben és a BSF oszcillátorban, TSFR-ben 
Tanulmányoztuk reakció-diffúzió frontok terjedését $\mathrm{H}^{+}$autokatalízis reakciókban és megállapítottuk egy $\mathrm{H}^{+}$-elvonó reakció (negatív visszacsatolás) a reakciózóna lokalizálódását és felhasadását okozza. ${ }^{16} \mathrm{~A}$ zárt gélreaktorban, a CDIMA reakcióval (klórdioxid-jód-malonsav-polivinilalkohol) sikerült hullámokat és kvázi-stacionárius (30-40 percig fennmaradó) mintázatokat létrehoznunk. ${ }^{17} \mathrm{Ez}$ a reaktortípus különösen alkalmas demonstrációs célokra: összeállítása nem igényel speciális felszerelést, számos egzotikus térbeni jelenség (pl. hullámok és hexagonális elrendezésű pöttyök kölcsönhatása, vagy struktúrákban kémiai módosítással kiváltott hullámhossz növekedés) is tanulmányozható.

A reakció-diffúzió rendszerek vizsgálatára vonatkozó kutatómunkánkat 2020-ban új reaktor típus tervezésével és tesztelésével folytattuk. ${ }^{26}$

\section{Nemlineáris kémiai dinamikai jelenségek modellezése és szimulációja}

A kétszubsztrátos pH-oszcillátorok CSTR-ben mutatott dinamikáját leíró Rábai-féle modellt ${ }^{18}$ módosítottuk olyan formába, amely nyitott-, félig-zárt és zárt-konfigurációjú pH-oszcillátorok viselkedésének leírására is alkalmas. ${ }^{19}$

A kétszubsztrátos pH-oszcillátorok legfontosabb részreakciójának, az oxidálószer és szulfition autokatalitikus reakció három variánsának (oxidálószerek: $\mathrm{IO}_{3}^{-}, \mathrm{BrO}_{3}^{-}$és $\mathrm{H}_{2} \mathrm{O}_{2}$ ) jellegzetességeit tanulmányozva meghatároztuk a $\mathrm{pH}$ vs idő görbék alakját befolyásoló paramétereket. ${ }^{20}$

Az OSFR-ben előállítható reakció-diffúzió szerkezetek létrejöttének elméleti alapjait numerikusan vizsgálva megállapítottuk, hogy a köbös autokatalizissel lejátszódó $\mathrm{A}+2 \mathrm{~B}=3 \mathrm{~B}$ reakcióval leírható kémiai folyamat, OSFR-ben vezetve, RD-tipusú stacionárius mintázat kialakulását eredményezi, ha a $\mathrm{B}$ diffúziósebessége több mint kétszer nagyobb, mint az A diffúziója. ${ }^{21}$

Numerikus szimulációkkal részletesen elemeztük a reakciózónaként funkcionáló gél vastagságának a kialakuló dinamikai viselkedésmódra gyakorolt hatását, amit kísérletekben csak körülményesen, nem elég finom felbontásban tudunk megtenni. Szimulálva a kétszubsztrátos $\mathrm{pH}$-oszcillátor modell viselkedését az OSFR-re jellemző paraméterek mellett egyértelmü, hogy a kialakuló állapot függ az alkalmazott gélvastagságtól. Azonos körülmények között változtatva a gél vastagságát, előbb térbeni bistabilitás, növelésével oszcillációk, majd komplex formák jelennek meg. Szimulációk szerint - és kísérletileg is - az autokatalitikus speciesz reverzibilis megkötése esetén stacionárius mintázat alakul ki. ${ }^{22}$

A pH-oszcillátorokkal és a reakció-diffúzió struktúrák előállításával kapcsolatos eredményeink elismerésének tartjuk, hogy - föszerkesztöi meghívásra - két cikkünk jelenthetett meg a magas hatástényezöjü (i.f. 24) Accounts of Chemical Research folyóiratban, ,pH-Regulated Chemical Oscillators”23 és „Designing Stationary Reaction-Diffusion Patterns in
pH-Activated Systems" ${ }^{24}$ címmel. Az itt közölt cikkek föként a szerzők saját munkáján és eredményein alapuló összefoglalók, de utalnak a témában más kutatók által eddig elért eredményekre és a témakör jövőbeni perspektívájára is. Az egyik „Account” cikkünk az összes ma ismert pH-oszcillátort (24 rendszert) kategorizálja, az alaptípusok müködésére általános vázmechanizmust javasol, tárgyalja a tudományos és technikai célú alkalmazásukat. A másik közlemény a szerzők által kifejlesztett módszert tárgyalja, amellyel reakció-diffúzió struktúrák laboratóriumi előállítása tervezhető.

\section{Összefoglalás}

A 2012 és 2020 között végzett kutatómunkánk során olyan új kémiai rendszereket terveztünk, állítottunk elő és tanulmányoztunk, amelyekben időben és/vagy térben spontán lejátszódó önszerveződés - koncentráció oszcilláció, vagy periodikus reakció-diffúzió szerkezet kialakulása figyelhető meg. Az új rendszereink összetételükben vagy az alkalmazott reaktor típusában különböznek a korábban ismertektől. Kimutattuk, hogy az oszcilláló rendszerekben eddig még nem alkalmazott reakciótípus, az aminosavak $\mathrm{KMnO}_{4}$-os oxidációja, áramlásos reaktorban oszcillációs kinetikával is lejátszódhat. Előállítottuk a perborátos oxidáción alapuló oszcilláló kémiai rendszerek első két képviselőjét. Mechanizmust javasoltunk és szimulációkat végeztünk a dinamikai viselkedésük leírására. Új dinamikai jelenségeket - oszcilláló specieseloszlást a $\mathrm{Ni}^{2+}+$ hisztidin közötti lépcsőzetes komplexképzési reakcióban és periodikus váltakozást a $\mathrm{Co}$ (hisztidin) ${ }_{2}$ komplex központi ionjának oxidációs számában - indukáltunk pH-oszcillátor és a céliont tartalmazó pH-érzékeny egyensúlyi reakció kapcsolásával kialakított összetett rendszerekben. Nyitott rendszerben müködő $\mathrm{pH}$-oszcillátorokat zárt rendszerüvé alakítottuk, amely elrendezés a pH-oszcillátorok alkalmazásában előnyösebb az áramlásos változatnál. Változatos formájú mozgó és stacionárius reakció-diffúzió szerkezetek kifejlesztését valósítottuk meg egy- és kétoldalról táplált gélreaktorokban Landolt típusú reakciót, minimális bromát oszcillátort, $\mathrm{pH}$-oszcillátort és csapadékos reakciót alkalmazva. Az elöállított időben és térben periodikus új rendszerek és a kapcsolódó alrendszerek dinamikáját részletesen tanulmányoztuk, kémiai hátterüket elemeztük, mechanizmusukat tisztáztuk és elvégeztük a dinamikai viselkedésüket leíró szimulációkat.

\section{Köszönetnyilvánítás}

A kutatómunkánkban való jelentős közremüködésükért a szerzők köszönetüket fejezik ki külföldi kooperációs partnereinknek, I. R. Epstein professzornak (Brandeis University, Waltham, MA, USA), P. De Kepper professzornak (CNRS Bordeaux, Franciaország) és a doktori vagy szaklaboratóriumi munkájukat kutatócsoportunkban végzett hallgatóknak (Horváth Viktor, Poros Eszter, Molnár István, Dúzs Brigitta, Csepiova Julianna, Nagyváradi Eszter). Kutatásainkhoz anyagi támogatást a 100891 sz. OTKA pályázat, és a 119360 sz. NKFI pályázat biztosította. 


\section{Hivatkozások}

1. Csörgeiné Kurin K.; Szalai I.; Orbán M.: „A nemlineáris kémiai dinamikai jelenségek kutatása az ELTE Analitikai Kémiai Tanszékén". Magy. Kém. Foly. 2012, 118, 46-54.

2. Poros E.; Kurin-Csörgei K.; Szalai I.; Orban M.: "Oscillations in the permanganate oxidation of gycine in a stirred flow reactor." J. Phys. Chem. A, 2013, 117, 9023-9027. https://doi.org/10.1021/jp4071345

3. Kurin-Csörgei K; Epstein I. R.; Orban M.: „Systematic design of chemical oscillators using complexation and precipitation equilibria". Nature, 2005, 433, 139-142. https://doi.org/10.1038/nature03214

4. Poros E.; Kurin-Csörgei K.; Szalai I.; Horvath V.; Orban M.: „Periodic changes in the distribution of species observed in the $\mathrm{Ni}$ - Histidine equilibrium coupled to the $\mathrm{BrO}_{3}-\mathrm{SO}_{3}{ }^{2-} \mathrm{pH}$-oscillator". J. Phys. Chem. A, 2014, 118, 6749-6756. https://doi.org/10.1021/jp504902v

5. Kurin-Csörgei K.; Poros E.; Csepiova J.; Orban M.: „Periodic changes in the oxidation states of the center ion in the cobalt histidine complex induced in the $\mathrm{BrO}_{3}-\mathrm{SO}_{3}{ }^{2-} \mathrm{pH}$-oscillator". Chaos, 2018, 28, 053114. https://doi.org/10.1063/1.5024461

6. Jang J. H.; Orban M.; Wang,S.; Huh, D.S.: „Absorrption-desorption oscillations of nanoparticles on a honycomb patterned $\mathrm{pH}$-responsive hydrogel surface in a closed reaction system". Phys. Chem. Chem. Phys. 2014, 16, 25296-25305. https://doi.org/10.1039/C4CP03083D

7. Poros E.; Horvath V.; Kurin-Csörgei K; Epstein I. R.; Orban M.: „Generation of $\mathrm{pH}$-oscillations in closed chemical systems: Method and applications.” J. Am. Chem. Soc. 2011, 133, 7174-7179. https://doi.org/10.1021/ja2010835

8. Poros E.; Kurin-Csörgei K.; Szalai I.; Rabai Gy.; Orban M.: ,pH-Oscillations in the bromate - sulfite reaction in semibatch and gel-fed batch reaction". Chaos, 2015, 25, 064602. https://doi.org/10.1063/1.4921176

9. Kurin-Csörgei K; Epstein I. R.; Orban M.: „Periodic pulses of calcium ions in a chemical system". J. Phys. Chem. A, 2006, 110, 7588-7592. https://doi.org/10.1021/jp0625311

10. Molnar I.; Kurin-Csörgei K.; Orban M.; Szalai I.:" Generation of spatiotemporal calcium patterns by coupling a $\mathrm{pH}$-oscillator to a complexation equilibrium”. Chem. Commun. 2014, 50, 4158-4160. https://doi.org/10.1039/C4CC00199K

11. Molnar I.; Kurin-Csörgei K.; Szalai I.: „Spatiotemporal dynamics of minimal bromate oscillators in an open one-side-fed reactor". Phys. Chem. Chem. Phys. 2018, 20, 13851-13857. https://doi.org/10.1039/C8CP01953C

12. Szalai I.: „Spatiotemporal behavior induced by differential diffusion in Landolt systems". J. Phys. Chem. A, 2014, 118, 10699-10705. https://doi.org/10.1021/jp508836p
13. Duzs B.; Lagzi I.; Szalai I.: „Propagating fronts and morphological instabilities in a precipitation reaction". Langmuir, 2014, 30, 5460-5465. https://doi.org/10.1021/la500707b

14. Duzs B., Szalai I. „Design of localized spatiotemperal pH patterns by means of antagonistic chemical gradients". RSC Advances, 2018, 8, 41756-41761. https://doi.org/10.1039/C8RA08028C

15. Wolpert L.: „Positional information and the spatial pattern of cellular differentiation", J. Theor. Biol. 1969, 25(1), 1-47. https://doi.org/10.1007/BFb0070164

16. Duzs B.; Szalai I.: „Front dynamics of pH-oscillators with initially separated reactants". React. Kinet. Mech. Catal. 2018, 123:2, 335-349. https://doi.org/10.1007/s11144-017-1329-1

17. Duzs B.; De Kepper P.; Szalai I.: „Turing patterns and waves in closed two-layer gel reactions". ACS Omega, 4:7p, 2019, 3213-3219. https://doi.org/10.1021/acsomega.8b02997

18. Rabai Gy.: „, Modeling and designing of $\mathrm{pH}$-controlled bistability, oscillations and chaos in a continuous-flow stirred tank reactor". ACH Models Chem. 1998, 135, 381-392.

19. Szalai I.; Kurin-Csörgei.; Orban M.: „Modeling pH-oscillators in open, semibatch and batch reactors". React. Kinet. Mech. Catal. 2012, 106, 257-266. https://doi.org/10.1007/s11144-012-0468-7

20. Molnar I.; Takacs N.; Kurin-Csörgei K.; Orban M.; Szalai I.: „Some general features in the autocatalytic reaction between sulfite ion and different oxidants". Intern. J. Chem. Kinet. 2013, 45, 462-468. https://doi.org/10.1002/kin.20782

21. Szalai I.: „Linear diffusive feed approach to explaining long range activation induced oscillations". React. Kinet. Mech. Catal. 2014, 111, 431-432. https://doi.org/10.1007/s11144-013-0665-z

22. Szalai I.; Horvath J. De Kepper P.: „, Contribution to an effective design method for stationary reaction-diffusion patterns". Chaos, 2015, 26(6), 064311. https://doi.org/10.1063/1.4921721

23. Orban M., Kurin-Csörgei K. Epstein I. R.: , pH-Regulated chemical oscillators". Acc. Chem. Res. 2015, 48(3), 593-601. https://doi.org/10.1021/ar5004237

24. Horvath J., Szalai I., De Kepper P.: „Designing stationary reactiondiffusion patterns in self-activated systems". Acc. Chem. Res. 2018 51(12), 3183-3190. https://doi.org/10.1021/acs.accounts.8b00441

25. Kurin-Csörgei K., Poros-Tarcali E., Molnár I., Orbán M., Szalai I. „Chemical oscillations with sodium perborate as oxidant”. Front. Chem. 2020, 8, 889-897. https://doi.org/10.3389/fchem.2020.561788

26. Dúzs B., Szalai I. „A simple hydrogel device with flow-through channels to maintain dissipative non-equilibrium phenomena". Comm. Chem. 2020, 3, 1-6. https://doi.org/10.1038/s42004-020-00420-y 


\section{Research on "the phenomena of nonlinear chemical dynamics" at the Department of Analytical Chemisrty, Eötvös University, II. (2012 - 2020)}

In an earlier paper published in this journal in 2012 we gave a concise account about our research activity pursued on the field of "nonlinear chemical dynamics" for about four decades $(1972$ - 2011) at the Department of Analytical Chemistry, Eötvös University. This research aimed at producing, analysing and characterising chemical systems which are capable of undergoing spontaneous self-organisations in time and/or space, giving rise to appearance of nonlinear phenomena, like concentration oscillations in stirred solution or formation of periodic patterns if the reaction takes place a thin solution layer or in a gel matrix. The most important outcomes of our research prior to 2011 were the discovery of several families of the oscillatory rections with numerous members in each group and observation of various moving and stationary reaction-diffusion (RD) structures.

During the time period between 2012 and 2020 we continued working on the same project and further information was collected about the self-assemblies that can arise in autonomous chemical systems. Our final goal was (and it still is) to establish general rules and laws that govern and fully explain the rhytmic chemical phenomena. Our research was focused on the following subjects: to seek after new versions of oscillating reactions that, in certain aspects (e.g. composition, applied reactor configuration, dynamics,..) differ from those discovered previously; to invent and use gel reactors for producing novel periodic spatial structures; to perform model calculations and simulations to describe, explain or to predict nonlinear phenomena that can occur in chemical systems under out-of-equilibrium conditions.

We succeeded in extending the number and variety of the oscillatory chemical reactions with two subgroups. Within the manganese chemistry based oscillators only inorganic compounds were used earlier as reductant. We showed that some amino acids (glycine, threonine, aspartic acid) can also play the role of substrate in permanganate oscillators. The $\mathrm{KMnO}_{4}$ oxidation of glycine was demonstrated to take place with oscillatory kinetics if the reaction is run in flow reactor at $\mathrm{T}=45^{\circ} \mathrm{C}$ in presencee of $\mathrm{PO}_{4}{ }^{3-}$ ions. At near neutral $\mathrm{pHs}$ sustained oscillations were recorded in the potential of a Pt electrode and in the light absorbance at the wavelengths characteriscic for following the autocatalytic species, the soluble $[\mathrm{Mn}(\mathrm{IV})]$ and the reagent $\left[\mathrm{MnO}_{4}{ }^{-}\right]$in time. Mechanism and a simple model were suggested which qalitatively explain the experimental observations in batch and in flow systems.

The peroxo compounds $\mathrm{H}_{2} \mathrm{O}_{2}$ and $\mathrm{K}_{2} \mathrm{~S}_{2} \mathrm{O}_{8}$ represent one of the key constituents in many chemical oscillators. It was proven that sodium perborate $\left(\mathrm{NaBO}_{3}\right)$ which is a mild oxidant compared to the more effective $\mathrm{H}_{2} \mathrm{O}_{2}$ and $\mathrm{K}_{2} \mathrm{~S}_{2} \mathrm{O}_{8}$ can also act as alternative oxidizing agent in bringing about oscillations in chemical systems. We were successful with developing two perborate oscillators by substitution of $\mathrm{H}_{2} \mathrm{O}_{2}$ with $\mathrm{NaBO}_{3}$ in the $\mathrm{Cu}(\mathrm{II})$-catalysed $\mathrm{H}_{2} \mathrm{O}_{2}-\mathrm{S}_{2} \mathrm{O}_{3}{ }^{2-}$ and $\mathrm{H}_{2} \mathrm{O}_{2}-\mathrm{SCN}^{-}$reactions. The $\mathrm{BO}_{3}^{-}-\mathrm{S}_{2} \mathrm{O}_{3}{ }^{2-}-\mathrm{Cu}(\mathrm{II})$ system oscillates only in flow $(\mathrm{Pt}$ and $\mathrm{pH})$, the $\mathrm{BO}_{3}^{-}-\mathrm{SCN}^{-}-\mathrm{Cu}(\mathrm{II})$ does only in batch at $\mathrm{pH}>9-10$. Mechanism was proposed, in which the role of intermediates $(\mathrm{HO})_{3} \mathrm{~B}(\mathrm{OOH})^{-}$and $(\mathrm{HO})_{2} \mathrm{~B}(\mathrm{OOH})_{2}{ }^{-}$that are dominant species at the oscillatory $\mathrm{pHs}$ was pointed out. In spite of the significant difference in the oxidation power of $\mathrm{H}_{2} \mathrm{O}_{2}$ and $\mathrm{NaBO}_{3}$ we assume that non-linearity originetes from the peroxo group present in both oxidants, therefore the set of reactions which produces the oscillatory dynamics may be similar or even identical in the $\mathrm{BO}_{3}^{-}$and $\mathrm{H}_{2} \mathrm{O}_{2}$ oscillators. In the repertoire of liquid phase oscillators these systems can be considered to be borate-mediated peroxide oscillators.
Induced oscillations were generated in combined systems comprising of the $\mathrm{BrO}_{3}{ }^{-}-\mathrm{SO}_{3}{ }^{2-} \mathrm{pH}$-oscillator coupled to $\mathrm{pH}$-dependent complex formation between histidine and $\mathrm{Ni}^{2+}$ or $\mathrm{Co}^{2+}$ ions. The primery oscillator which operates between $\mathrm{pH} 3$ and 7 was proven to be capable of forcing these $\mathrm{pH}$-sensitive equilibra to alternate periodically between the unreacted and the fully complexed states. The repetitive interconversions gave rise to two additional nonlinear phenomena, the oscillatory distribution of species $\left[\mathrm{Ni}^{2+}\right],\left[\mathrm{NiHis}{ }^{+}\right]$and $\left[\mathrm{Ni}(\mathrm{His})_{2}\right]$ formed at various $\mathrm{pHs}$ and resulted in periodic changes of the oxidation number of the central Co-ion in the Co-chelate between +2 and +3 with the frequency of the $\mathrm{pH}$-oscillations. Rhytmic phenomenon was induced in physical property as well. With our contribution oscillatory adsorpion desorption of Ag-nanoparticles on the surface of a specially fabricated $\mathrm{pH}$-responsive hydrogel film was shown to occur when it was immersed in the FIS pH-oscillator.

All oscillators known up to date were discovered in a CSTR. In some suggested practical applications (e.g. construction of pulsating drog delivery device, molecular motors,..) batch $\mathrm{pH}$-oscillator would be preferred to use. With our earlier proposed method we transformed three CSTR pH-oscillators to the form which funcioned under closed experimental conditions. Recently, we added two more members, the $\mathrm{BrO}_{3}{ }^{-}-\mathrm{SO}_{3}{ }^{2-}-\mathrm{H}^{+}$and the $\mathrm{Cu}$ (II)-catalysed $\mathrm{S}_{2} \mathrm{O}_{8}{ }^{2-}-\mathrm{S}_{2} \mathrm{O}_{3}^{2-}-\mathrm{NH}_{4} \mathrm{OH}$ systems to the group of the batch-like $\mathrm{pH}$-oscillators. In this configuration a beaker equipped with a combined glass electrode served as reactor, which contained the solution mixture of oxidant $\mathrm{BrO}_{3}{ }^{-}$and $\mathrm{H}^{+}$or $\mathrm{S}_{2} \mathrm{O}_{8}{ }^{2-}-\mathrm{NH}_{4} \mathrm{OH}-$ $\mathrm{Cu}(\mathrm{II})$ in stochiometric excess and the reductants $\mathrm{SO}_{3}{ }^{2-}$ and $\mathrm{S}_{2} \mathrm{O}_{3}{ }^{2-}$ consumed during a pH-oscillatory cycle was ensured by dissolution from a silica gel layer prepared previously in the beaker in presence of high concentrationof the reductant. The semibatch version of the two oscillators (here the reductants were introduced to the solution of the oxidant with very slow and uniform rate) which represent an intermediate oscillatory state between the flow and batch systems, was also produced and used for prediction of the optimum conditions required for the gel-fed reactor to operate. Model calculations were done to describe the oscillatory behavior observed in batch, semibatch and flow systems.

Wide variety of spatiotemporal patterns were generated using different type of reactor configurations and chemical systems in which nonlinearity is involved.

We have shown that sustained spatiotemporal $\mathrm{pH}$ and calcium patterns can be produced by coupling two modules, the bromate-sulfite-ferrocyanide $\mathrm{pH}$-oscillator and the $\mathrm{pH}$-sensitive complexation of $\mathrm{Ca}^{2+}$ by ethylenediaminetetraacetate. In the coupled system, we observed stabilization of localized spots that indicates that the feedback of the CaEDTA equilibrium slows down the effective diffusivity of hydrogen ions, most likely due to a possible interaction of CaEDTA with the agarose matrix. Our results emphasize the importance of interaction between the two coupled subsystems.

Minimal bromate oscillators represent the simplest version of the oscillatory reactions based on the chemistry of the oxybromine species. We presented numerical and experimental evidence of the existence of reaction-diffusion waves in the ferroin catalyzed minimal bromate oscillator. The wave dynamics depends not only on the characteristic chemical time scales but also on those of the diffusive matter exchange which occurs between the reaction-diffusion medium and its environment. We have shown that the extended reactivity of the ferroin catalyst compared to the $\mathrm{Ce}(\mathrm{IV})$ towards the oxybromine species plays an essential role in the observed phenomena. 
The spatiotemporal dynamics of the Landolt-type $\mathrm{pH}$ oscillators have been explored with initially separated reagents in space. The generic Rábai model of the $\mathrm{pH}$-oscillators predicts the formation of an asymmetric acidic domain at the interface of the two zones loaded by different sets of chemicals. This asymmetry is caused by the initial conditions rather than the difference in the diffusivities of the components. As the influence of the negative feedback process increases, this acidic zone becomes localized around the interface. At some point, the acidic zone bifurcates, a less acidic zone separates and starts to move forward to the oxidant rich zone. In a limited domain of parameters, spatiotemporal oscillations appear due to the instability of the main acidic zone. The appropriate conditions for the development of this periodic behavior were predicted by simulations. The numerically predicted phenomena except the oscillations were supported by experiments performed in the bromate-sulfite-ferrocyanide and in the hydrogen peroxide-sulfite-ferrocyanide systems.

We have designed reaction-diffusion waves and stationary Turing patterns in closed two-layer gel reactors, where the two compartments are initially filled with complementary sets of reactants of the chlorine dioxide-iodine-malonic acid-poly(vinyl alcohol) reaction. The asymmetrical loading generates concentration gradients and the patterns form at the interface between the two parts. These easy-to-perform experiments allow us to study a wide range of dynamical phenomena without requiring a specific reactor design or the use of sophisticated equipment. To get complementary information on pattern formation in parallel and perpendicular to the direction of the concentration gradients, two geometrically different configurations of compartments are presented. We demonstrate that three variants of the initial distribution of the chemicals can be equally applied, and this flexibility provides a way to introduce additional reagents to perturb the dynamics of the systems.

We successfully generated spatially localized moving and stationary $\mathrm{pH}$ patterns in two-side-fed reaction-diffusion systems. The patterns are sandwiched between two quiescent zones and positioned by the antagonistic gradients of the reactants of the self-activatory process. Spatial bistability, spatiotemporal oscillations, and formation of stationary Turing patterns have been predicted by numerical simulations and observed in experiments performed by using different hydrogen ion autocatalytic chemical systems. The two-side-fed geometry has been applied to study the dynamics of the $\mathrm{AlCl}_{3} / \mathrm{NaOH}$ precipitation system. We have observed temporal oscillations in the total mass of the precipitate, the formation of propagating and annihilating waves, and morphological instabilities. Importantly, these structures form in the lateral direction, contrary to the standard Liesgang phenomenon.

The results of additional numerical works related to the main subject of our poject (e.g. improvement of the Rabai model, prediction the effect of gel sickness on the dynamics, analysis of the oxidant - sulfite $\mathrm{H}^{+}$-autocatalytic reactions,..) are also presented. 